\title{
Software Educacional: Nematelmintos de Aquisição Passiva
}

\section{Educational Software: Passive Acquisition of Nemathelminthes}

Tatiana Damasceno Grincevicius ${ }^{I}$

Suzana Guimarães Moraes ${ }^{I}$

PALAVRAS-CHAVE

- Parasitologia;

- Helmintos

- Educação em Saúde;

- Software;

- Educação Médica.

\section{KEYWORDS}

- Parasitology;

- Roundworms;

- Health Education;

- Software;

- Medical Education.

Recebido em: 27/01/2015

Aprovado em: 21/12/2015

\section{ABSTRACT}

Object: The main objective of this project is to evaluate and develop educational software utilizing Helminth parasitological images to interactively illustrate the passive transmission of roundworms. This can be useful to teachers, professionals and graduate students from various health professions understand and identify these worms as well as for use by professionals in their practice. Methodology: The software was built using Multimedia Flash ${ }^{\hat{a}}$ and a database of images. This enabled the creation of animations and simulations in vector language, resulting in smaller files that can be made available through the web or provided on other storage media. The final product was evaluated by medical students. Results: The software has been completed and has been favorably evaluated by medicine students $(n=97)$ of the PUC/SP Medical Science and Health School. Their tests compared results before use of the software with results obtained after using the software. A consistent growth of knowledge was demonstrated either by self-assessment or closed objective questions. Conclusion: The results obtained allow us to conclude that the software is of great educational interest and should be useful to students, teachers and professionals in the health field. 


\section{INTRODUÇÃO}

Historicamente, a formação dos profissionais de saúde tem sido pautada no uso de metodologias conservadoras (ou tradicionais), sob forte influência do mecanismo de inspiração cartesiana newtoniana, fragmentado e reducionista ${ }^{1}$.

Nesse sentido, o processo ensino-aprendizagem tem se restringido, muitas vezes, à reprodução do conhecimento, na qual o docente assume o papel de transmissor de conteúdos, ao passo que ao discente cabem a retenção e a repetição dos mesmos - numa atitude passiva e receptiva -, tornando-se mero espectador, sem a necessária crítica e reflexão².

O desafio das escolas formadoras de profissionais da saúde é prepará-los com conhecimento, habilidades e atitudes para que atuem de forma qualificada sobre as necessidades em saúde do ser humano. O modo de ensinar tem evoluído através dos tempos, e toda transformação passa por inquietações, reflexões e mudanças de concepção. Ao frequentar o curso de graduação na área da saúde, o aluno tem na escola o estudo e na atividade prática o trabalho. Para que esse processo ocorra de forma interativa entre a autonomia docente e o potencial dos discentes na construção do seu conhecimento, tem havido mudanças no ensino presencial tradicional ${ }^{3}$.

O ensino no Brasil e no mundo está passando por transformações, e o modelo tradicional está sendo substituído por modelos educacionais inovadores, o que tem ocasionado mudanças no papel do docente. O ensino baseado na transmissão de conhecimentos, no qual o professor se enquadra como especialista no assunto e o estudante como observador, já não mais se adéqua às necessidades de formação de profissionais de saúde ${ }^{4}$.

No Brasil, as Diretrizes Curriculares Nacionais (DCN) para os cursos de Medicina trazem no artigo $9^{\circ}$ que os professores devem ser facilitadores, mediadores do processo ensino-aprendizagem ${ }^{5}$. A tendência é a substituição de metodologias de ensino com foco no professor por metodologias centradas no estudante, visando a uma aprendizagem mais significativa e ao desenvolvimento da capacidade crítica e reflexiva dos profissionais de saúde ${ }^{6}$.

Quando o ensino é centrado no professor e na transmissão do conhecimento, o estudante torna-se mais propício a reproduzir o conhecimento obtido por meio de uma aprendizagem superficial ${ }^{7}$.Quando o ensino é centrado no aluno, a profundidade da aprendizagem e a compreensão dos fenômenos estudados são maiores ${ }^{8}$.

Dessa forma, o professor deve estimular ao máximo a motivação dos alunos, despertando neles a busca pelo conhecimento, além do desenvolvimento de competências e habilidades. Nesse contexto, softwares educativos são muito utilizados como estratégias de aprendizagem ${ }^{9}$.
Segundo Fonseca ${ }^{10}$ e Ramos $^{11}$, a tecnologia pode atuar como facilitadora no processo de aprendizado, uma vez que revela inúmeras possibilidades com o uso de softwares educacionais que geram modelos e apresentam simulações que permitem ao aluno realizar os mais variados experimentos e explorações, desenvolvendo a flexibilidade cognitiva.

Tendo em vista que vêm aumentando as dificuldades de criar e manter laboratórios experimentais com animais, as ferramentas virtuais estão ganhando cada vez mais importância na educação nas profissões da saúde ${ }^{12,13}$.

Além da ética, deve-se levar em conta a questão econômica e prática na adoção de métodos alternativos. $\mathrm{O}$ valor despendido com o modelo biológico é alto, por requerer suporte técnico, equipamentos e espaço físico quando comparado às alternativas, que requerem investimento inicial, porém pouca manutenção ${ }^{14}$.

A principal finalidade da elaboração de um software educacional, do ponto de vista de Jucá ${ }^{15}$ e Kreutz $^{16}$, não é substituir o instrutor, mas, sim, ser um recurso auxiliar no ensino, permitindo o acesso a uma grande variedade de informações (por meio de imagens, vídeos e gráficos), e capacitar o aluno a ampliar seu conhecimento sobre determinado assunto de forma autonôma.

A saúde apresenta-se como um campo interdisciplinar com alta complexidade, pois requer conhecimentos e práticas de diferentes áreas: ambientais, clínicas, epidemiológicas, comportamentais, sociais e culturais ${ }^{17,18}$.

As tecnologias de informação (TI) e comunicação podem facilitar o processo interdisciplinar, pois apresentam uma série de vantagens em relação aos métodos convencionais de aprendizagem e facilitam a troca imediata de informações, a visualização de subtarefas como parte de tarefas mais globais, a adaptação da informação aos estilos individuais de aprendizagem, o encorajamento a maior exploração e melhor organização das ideias, maior integração e interação e maior poder de distribuição e comunicação nos mais variados contextos ${ }^{19}$.

As enteroparasitoses são consideradas um problema de saúde pública no Brasil e, habitualmente, estão associadas ao baixo nível socioeconômico da população. Representam fator importante na etiologia das anemias carenciais e da desnutrição proteico-calórica, pois um estado nutricional adequado depende não só da ingestão dos alimentos, mas também de sua utilização biológica eficiente, que pode estar comprometida em casos de infestação por enteroparasitas ${ }^{20,21}$.

Nos países em desenvolvimento como o Brasil, grande parte da população, devido às baixas condições socioeconômicas em que vive, fica exposta a diversas doenças debilitantes, como no caso das parasitoses intestinais, que acometem principalmente indivíduos das faixas etárias mais jovens da população ${ }^{22,23}$ 
As enteroparasitoses colaboram para o agravamento de quadros de desnutrição, diarreia, anemias, diminuição do desenvolvimento físico e do aproveitamento escolar das crianças. No entanto, embora muito se discuta sobre a importância das parasitoses intestinais, principalmente entre crianças em idade escolar, pouca atenção tem sido dada ao assunto nos programas de formação de educadores ${ }^{24-26}$.

Ascaridíase, tricuríase e algumas helmintíases intestinais estão listadas entre as doenças negligenciadas ou doenças tropicais negligenciadas, embora algumas não se restrinjam às regiões tropical e subtropical. São concentradas nas populações mais pobres, e muitas delas não exibem altas taxas de mortalidade, embora apresentem altas taxas de morbidade. Estima-se que de 20 a 30\% da população das Américas esteja infectada por Ascaris lumbricoides, Trichuris trichiura e outros helmintos ${ }^{27}$,confirmando que as geo-helmintíases ainda representam um relevante problema de saúde ${ }^{28}$.

Neste contexto, este trabalho visa apresentar um software educacional que poderá ser utilizado como ferramenta adicional às metodologias ativas de aprendizagem, como nas atividades prático-científicas, tendo em foco o ensino da parasitologia com ênfase em nematelmintos de transmissão passiva. Neste sentido, o ensino baseado na prática pode ser mais detalhado, é uma modalidade de metodologia ativa muito explorada em outras universidades.

\section{MATERIAL E MÉTODOS}

Foi garantida confidencialidade a todos os dados obtidos no trabalho. O presente estudo foi aprovado pelo Comitê de Ética e Pesquisa da Faculdade de Ciências Médicas e da Saúde da Pontifícia Universidade Católica de São Paulo, comnúmero de protocolo 418, no dia 8 de outubro de 2013.

Participaram da avaliação do software 97 alunos do curso de Medicina, todos do segundo ano.Para adequada avaliação da metodologia e ferramentas didáticas desenvolvidas no presente projeto, os voluntários utilizaram o software em ambiente controlado, ou seja, no laboratório de informática, em horário predeterminado, com um computador disponível para cada um, e foram submetidos a pré e pós-testes, assim como responderam a um instrumento de percepção.

Para a elaboração do software foram utilizadas imagens adquiridas das lâminas e sedimento fecal positivo do acervo de parasitologia da FCMS. As imagens macroscópicas foram captadas com uma câmera digital Panasonix Lumix DMC-ZS20 de uso pessoal, e as imagens microscópicas foram captadas através da câmera Nikon DS-Ril, acoplada a um fotomicroscópio Nikon Eclipse 800 (FCMS/PUC-SP).

Com base na definição do roteiro e planejamento iniciais, foram elaborados esquemas e textos necessários ao entendi- mento da evolução das doenças causadas pelos nematelmintos de aquisição passiva. Os esquemas foram desenvolvidos no autor de multimídia Flashâ.

O software foi desenvolvido no autor de multimídia Flashâ. Este programa permite a elaboração de animações e simulações em linguagem vetorial, resultando em arquivos com pequenos tamanhos, que podem ser disponibilizados através da web ou em mídias ópticas e magnéticas. O software agrupou as imagens, esquemas, textos e filmes subdivididos nos temas propostos.

Os alunos foram convidados pelo Moodle (Modular Object-Oriented Dynamic Learning Environment), ambiente virtual de comunicação acadêmica da FCMS, a participar de forma voluntária da avaliação do uso do software. O programa foi instalado na rede de computadores do Laboratório de Informática.

Para avaliar a aplicabilidade do software e o ganho cognitivo dos voluntários após a utilização do mesmo, os usuários foram convidados a responder, antes de manusearem o software, a um pré-testecomposto por dez questões objetivas fechadassobre os temas presentes no material didático. Não houve limite de tempo para a navegação ou para responderem aos instrumentos de avaliação.

Após tomarem contato com todo o material, os alunos responderam ao pós-teste, idênticoaopré-teste com relação aos conceitos e tema, para avaliar se houve modificação no grau de compreensão do tema apresentado.

Para avaliar o uso do software e complementar a avaliação de seu conteúdo, os usuários responderam, ao término do uso, a um instrumento de percepção caracterizado por avaliar as seguintes dimensões: importância da metodologia na formação profissional, qualidade do software, disponibilidade do software e eficiência da metodologia para o ensino da parasitologia. Os voluntários foram orientados a não deixar de se posicionar sobre nenhuma das asserções. Os dados pré e pós-teste foram testados quanto à normalidade pelo teste Shapiro-Wilk. A análise das asserções contidas no instrumento de percepção foi feita com o cálculo do coeficiente de correlação linear (r).

A avaliação técnica do software foi realizada pela equipe de TI do presente projeto de acordo com a norma NBR 13596, que determina as características de qualidade do software.

\section{RESULTADOS}

Com base em um roteiro escrito, foram definidas as três espécies - Ascaris lumbricoides, Enterobius vermicularis e Trichuris trichiura- e os respectivos recursos audiovisuais a serem abordados no software. Na etapa seguinte, para cada espécie foi elaborado o storyboard, com informações gráficas e visuais dos sete tópicos - agente causal, ciclo de vida, epidemiologia, aspectos clínicos, diagnóstico laboratorial, tratamento e profilaxia -, para contex- 


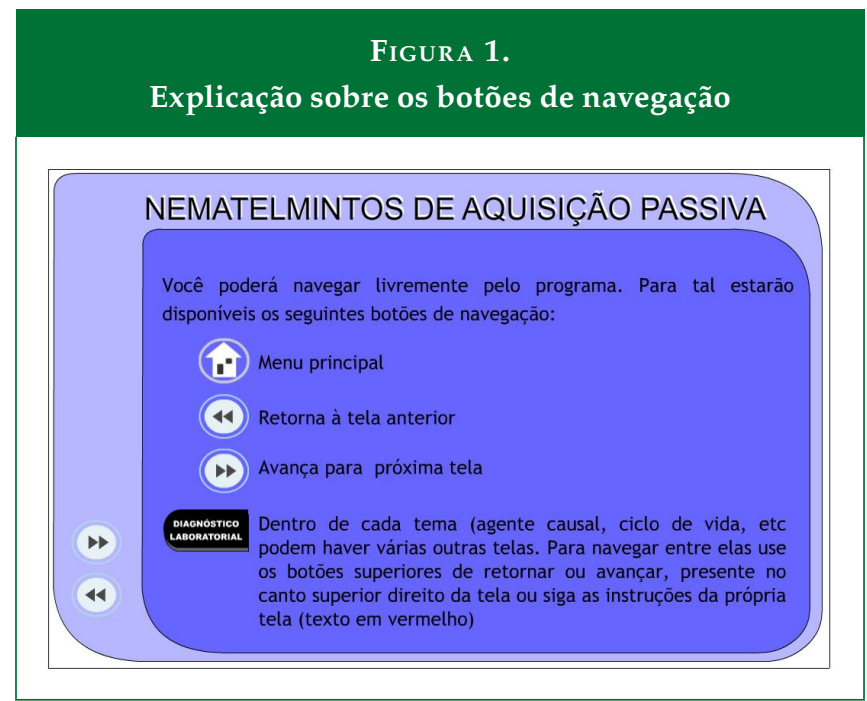

Fonte: O autor.

tualizar as imagens, estimular a curiosidade do usuário sobre o material ilustrado e promover o raciocínio clínico. Esse storyboard foi importante tanto para a definição dos elementos gráficos e mídia, quanto para a navegação entre as telas, possibilitando usar o software de forma autodirigida. Na elaboração do software foram utilizadas 21 fotos de própria autoria, e de autoria não própria foram usadas 18 fotos, 3 imagens de RX e 2 vídeos.
Os esquemas foram desenvolvidos no autor de multimídia Flashâ. Todas as formas de ilustração foram sempre acompanhadas de textos explicativos ou legendas, elaborados com base nos casos clínicos fictícios e na literatura existente, priorizando o aprendizado autodirigido e autônomo.

O software pode ser acessado no endereço eletrônico www.hainfotec.net.br/parasitologia. Ao todo, foram definidas 133 telas (frames), divididas em cinco temas. Cada tema contém uma quantidade de telas necessárias para alocar seu conteúdo didático,sendo 6 telas de introdução, 34 de Ascaris lumbricoides, 20 de Enterobius vermicularis e 23 de Trichuris trichiura, com conteúdo cognitivo e recursos audiovisuais ilustrando cada parágrafo, incluindo imagens estáticas e dinâmicas, tabelas e esquemas. Para o quizz, foram feitas 50 telas. O software inicia-se com uma tela de apresentação com o título "Nematelmintos de Aquisição Passiva", seguida pela apresentação do uso dos botões e tela de início da navegação com os temas a serem abordados (Figura1). O usuário observa, então, uma tela que explica os botões de navegação e é encaminhado à tela principal, com um título e uma pequena explanação sobre as fotos expostas. Continuando a navegação, o usuário vai para o menu principal, onde está ilustrado o conteúdo a ser abordado, e poderá acessar o material sobre as três espécies de parasitas e também ter acesso ao quizz. Já ao clicar em uma das espécies, como no "Enterobius vermicularis" (Figura 2), o usuário verá uma tela inicial com sete abas de direcionamento

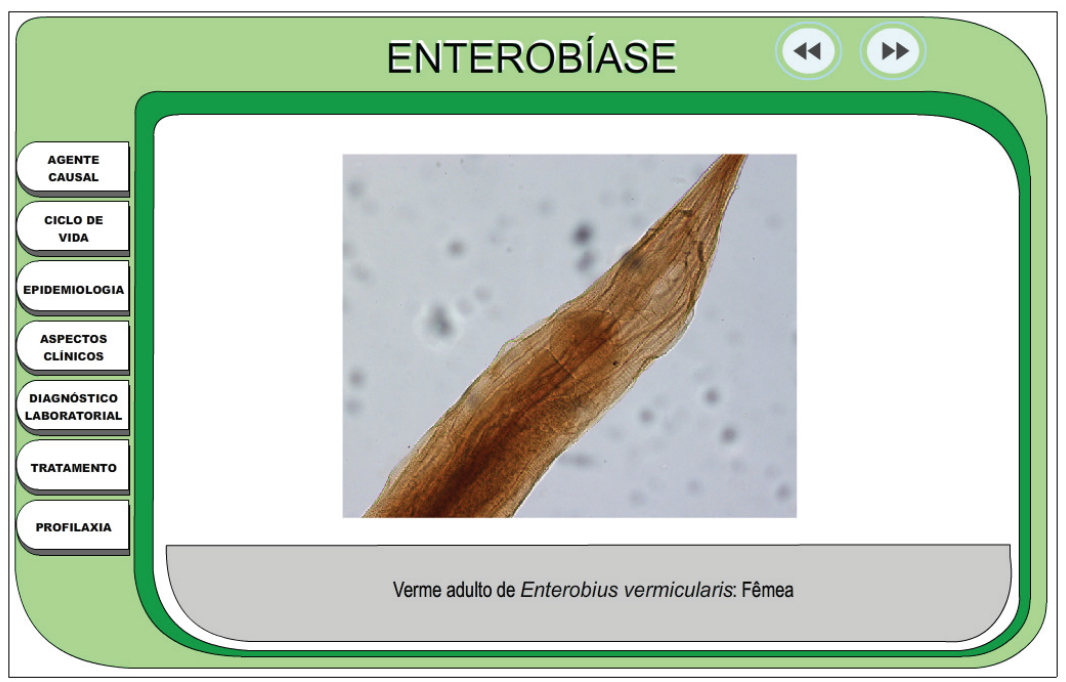

Fonte: O autor. 


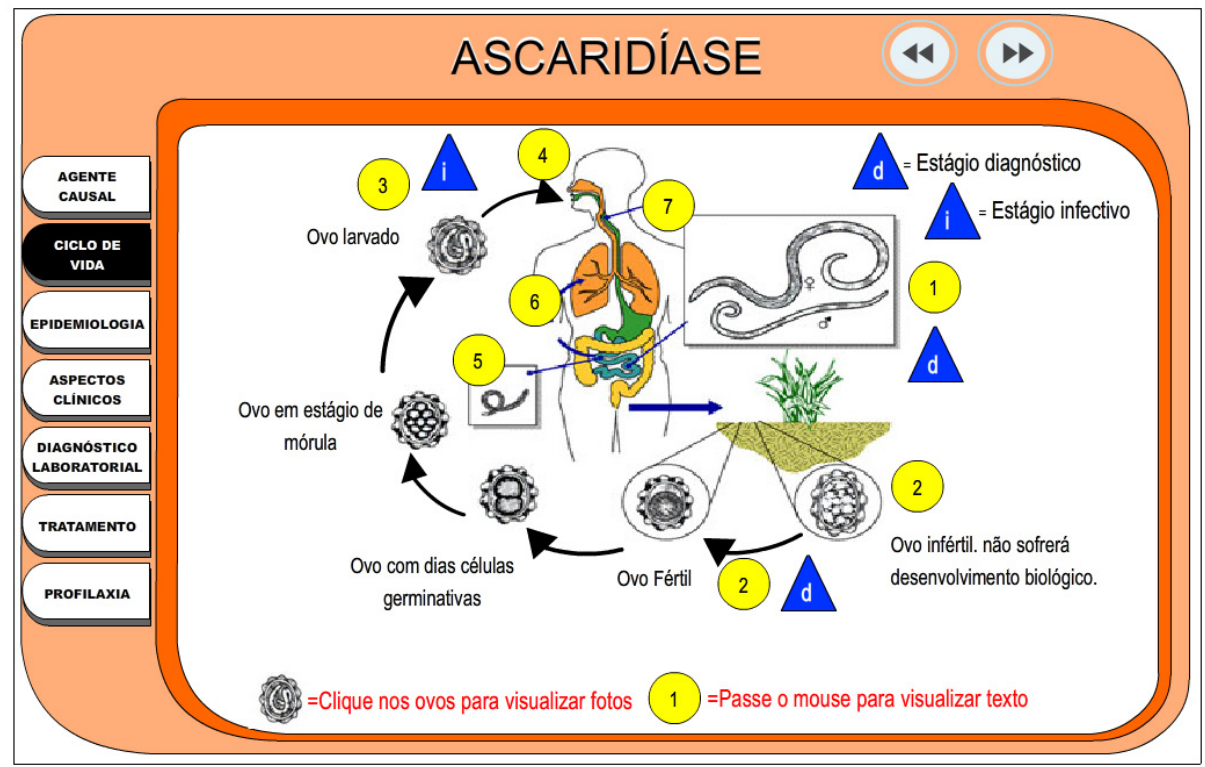

Fonte: O autor.

para outros subtemas (agente causal, ciclo de vida, epidemiologia, aspectos clínicos, diagnóstico laboratorial, tratamento e profilaxia) e foto macroscópica da patologia com breve texto explicativo.

Durante a navegação, existem algumas palavras em destaque (negrito ou itálico). Ao se passar o mouse sobre as mesmas (Figura 3), aparecerá seu significado, tendo o usuário uma ferramenta para termos desconhecidos.

Funcionalidade e acessibilidade foram outros aspectos analisados durante a criação visual da tela, já que uma simples mudança na posição de botões pode facilitar ou dificultar a navegação, principalmente quando se trata de um usuário inexperiente em ambientes interativos. Desta forma, o usuário se habitua mais rapidamente ao novo ambiente proposto.

De forma geral, o software foi muito bem avaliado pelos alunos que o testaram. Muitos fizeram elogios à metodologia de ensino, os resultados da avaliação do software foram bastante favoráveis, e os resultados comparativos do pré-teste e pós-teste mostraram progressos em todas as questões abordadas.

Os dados do pós-teste não apresentaram distribuição normal, portanto houve necessidade de usar um teste não paramétrico. Sendo assim, foi utilizado o "Teste do Sinal", unilateral, com alpha $=0,05$, que não assume simetria das diferenças entre as amostras ${ }^{29}$.
O resultado desta análise estatística mostrou que as diferenças entre pré e pós-teste foram altamente significativas, para $\mathrm{n}=$ 97, p<0,0001. Dos 97 voluntários, seis acertaram o mesmo número de questões no pré e no pós-teste, sendo estes desconsiderados pelo "Teste do Sinal". Apenas três voluntários acertaram maior número de questões no pré-teste em relação ao pós-teste. Observamos que para 88 voluntários o uso do software contribuiu para aumentar o conhecimento sobre o assunto abordado, pois acertaram maior número de questões no pós-teste.

Com relação às asserções, foram validadas 16 das 18 asserções inicialmente propostas. Apenas as asserções validadas foram usadas na análise subsequente. As duas asserções que apresentaram o r menor que 0,30 (asserções 5 e 15), e consequentemente não foram validadas, abordavam a forma de disponibilizar o software aos alunos.

\section{Médias das asserções e interpretação gráfica}

Caso a média da asserção apresente um valor entre 1,00 e 1,66, interpreta-se como uma atitude extremamente negativa frente à asserção, e alguma iniciativa deve ser tomada a respeito do conteúdo avaliado. Se estiver entre 1,67 e 3,33, é considerado um valor preocupante, e deve ser visto como um alerta para asserção afetada, e alguma solução também deve ser buscada. Já entre 3,34 e 5,00, interpreta-se como uma atitude positiva 
Figura 4.

Perfil atitudinal dos respondentes por asserção.

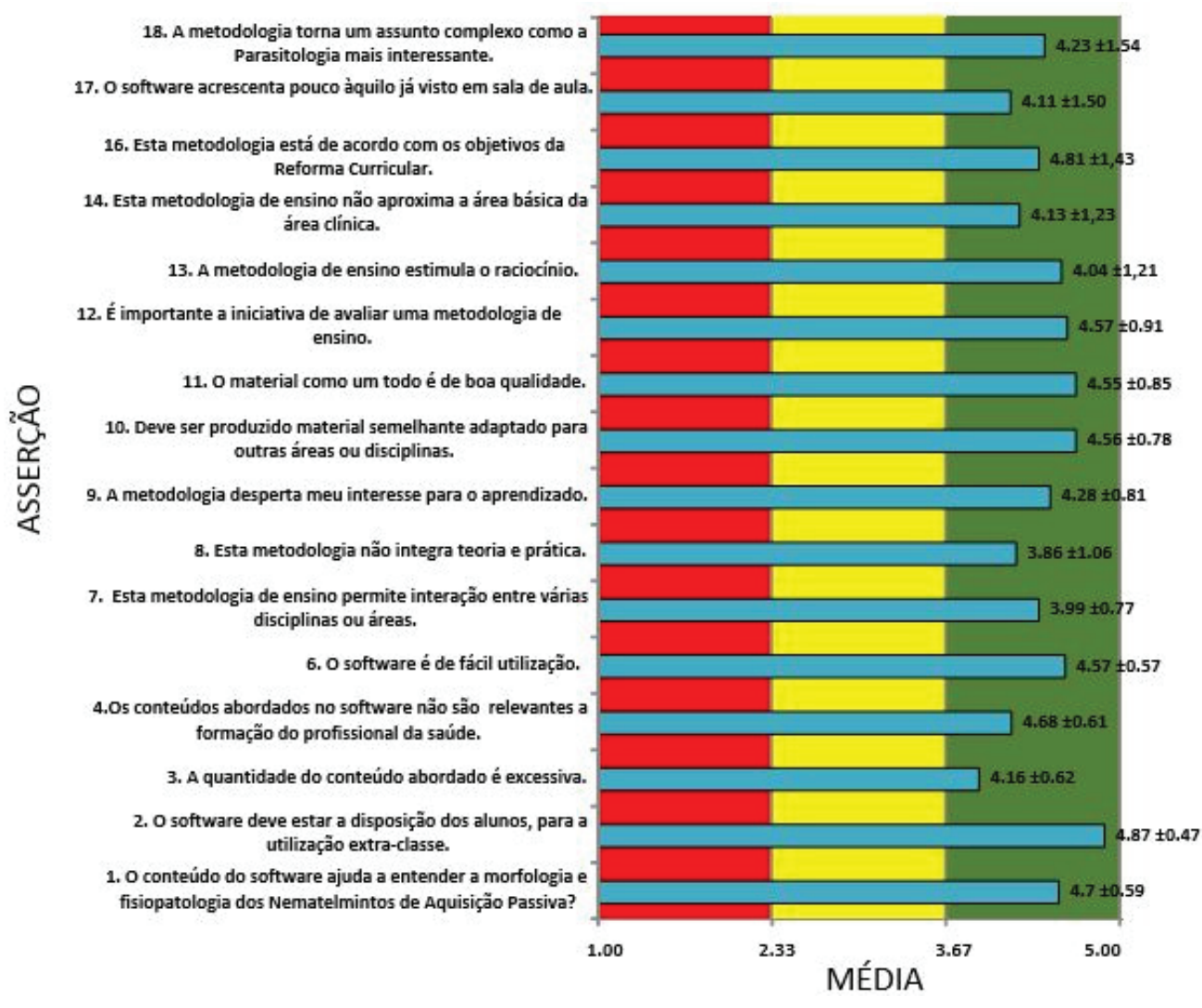

Fonte: $O$ autor.

com relação à asserção, e, neste caso, nenhuma medida urgente precisa ser adotada.

Com relação ao perfil atitudinal, apresenta as médias e desvio padrão das asserções validadas. É possível observar que, das asserções validadas,nenhuma obteve média na zona de alerta, ou seja, todas as médias foram superiores a 3,34. É possível observar que todas as asserções validadas se localizam na área de conforto. Apesar disso, algumas asserções apresentaram menores médias em relação às demais (Figura 4), como, por exemplo, a asserção que afirmava que a quantidade de conteúdo do software era excessiva. Tal observação pode decorrer do fato de os alunos terem utilizado todo o software em um único momento. Para minimizar esta situação, sugerimos que o software esteja disponível aos usuários em várias oportunidades ou seja utilizado como ferramenta didática em sustentações aplicadas.

Outra asserção com média inferior às demais foi a que afirma que o software não integra teoria e prática. Um acrésci- mo de outros temas e aplicações clínicas ao software, conforme sugestões relatadas em campo aberto do instrumento de percepção, poderia melhorar a avaliação desta asserção.

Vale ressaltar ainda as asserções mais bem pontuadas: “O software deve estar à disposição dos alunos, para utilização extraclasse"; "O software é de fácil utilização"; "O conteúdo do software ajuda a entender a morfologia e fisiopatologia dos nematelmintos de aquisição passiva". Isto demonstra o interesse dos discentes em ter acesso a este tipo de material didático em outros momentos e ambientes de aprendizagem, assim como ao desenvolvimento de metodologias semelhantes para outras áreas ou especialidades médicas.

Já a análise das dimensões também revelou que todas se localizam na área de conforto (Figura 5), ressaltando a qualidade e eficiência do material didático e da metodologia empregada para o entendimento das repercussões das parasitoses.

No campo aberto, foram observados vários comentários que enalteceram a metodologia empregada, ressaltando a va- 
lidade da pesquisa, assim como sugestões de aprimoramento e/ou complementação do software.

A análise do conteúdo descrito no campo aberto permitiu identificar possíveis melhorias que poderão ser implementadas no software, tendo em vista que a linguagem vetorial proporciona constante atualização do material. Esta etapa também valorizou a opinião dos usuários.

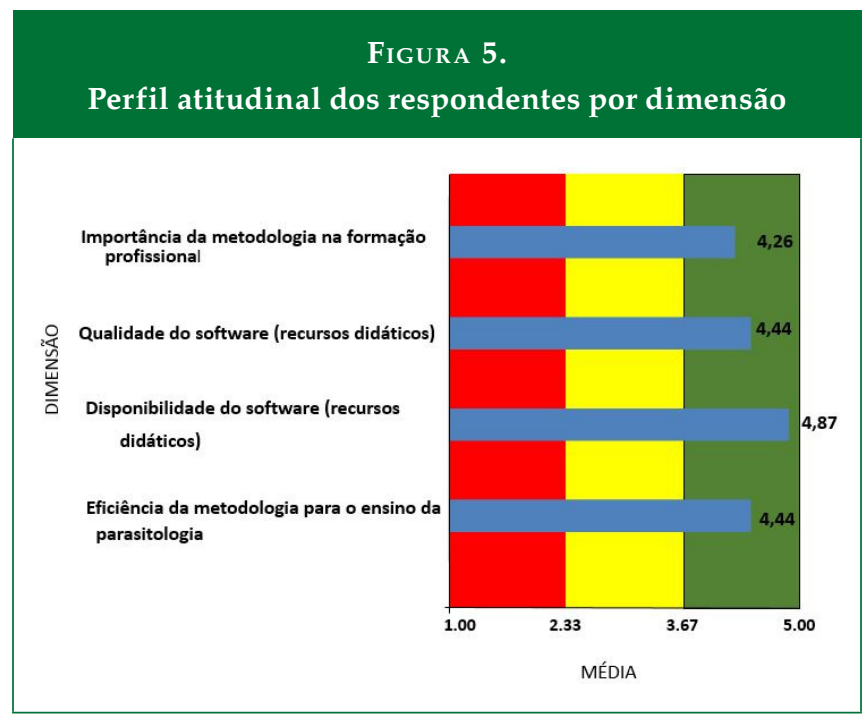

Fonte: $O$ autor.

\section{DISCUSSÃO}

Neste novo cenário, a educação convencional começou a ser questionada e pressionada no sentido de mudar as formas de transmitir e criar conhecimentos ${ }^{15}$. Neste ponto, as novas tecnologias da educação podem ajudar, não só facilitando o acesso a novos conhecimentos, mas também com ferramentas que auxiliem o processo ensino-aprendizagem, tornando-o mais eficiente e atraente ${ }^{15}$. Uma destas novas tecnologias são os softwares, que podem ser adaptados à prática educacional ${ }^{30}$. Esta ferramenta já vem sendo utilizada em várias áreas do processo ensino-aprendizagem e em várias áreas da saúde.

Em diversos países, a formação médica vem sendo discutida com vistas a adotar um currículo adequado à realidade dos sistemas de saúde. No Brasil, as Diretrizes Curriculares para os Cursos de Graduação em Medicina vêm acompanhando o contexto mundial de transformação de referenciais da educação e das políticas de saúde. Essas mudanças buscam uma nova orientação que possa contribuir para a formação do profissional que a sociedade contemporânea exige ${ }^{5}$.

O software desenvolvido nesta pesquisa permite a interação dos alunos com o programa, com autonomia, tendo como principal benefício o respeito ao ritmo de aprendizado de cada usuário. Além disso, permite comparar imagens estáticas e dinâmicas, relacionando-as com situações frequentemente encontradas na prática clínica.

É importante salientar a dificuldade de mostrar detalhes da morfologia de ovos e vermes adultos e suas repercussões clínicas de outra maneira, inclusive as imagens em movimento, para a demonstração da mucosa intestinal revestida pelos vermes, particularmente com potencial para alcançar um grande número de usuários interessados. Lembramos que existe um número crescente de alunos, contrastando com as limitações físicas das instituições de ensino (laboratórios experimentais).

A estratégia de utilizar imagens de casos comuns na prática clínica como elementos motivadores foi francamente favorável, na avaliação dos alunos. As avaliações de autopercepção ao instrumento de ensino-aprendizagem, bem como os relatos informais e abertos dos alunos que o testaram foram muito apreciativos. Embora todas as assertivas estivessem dentro da janela de uma avaliação positiva, pareceu-nos que o conteúdo do material didático foi de fato excessivo, especialmente em se tratando de uma única ocasião de manuseio. Como julgamos interessante que todo o conteúdo esteja presente, recomendamos trabalhar o material em mais de um momento, para que o aprendiz possa aproveitá-lo em toda a sua potencialidade. Não nos surpreendeu também que o item "o software acrescenta pouco àquilo já visto em sala de aula" tenha tido avaliação inferior à dos demais, pois, como já ressaltamos, este é um material complementar ao estudo-aprendizagem e não dispensa os momentos didáticos "tradicionais".

Com relação às avaliações somativas formais, ficou claro que a manipulação do software promoveu um acréscimo evidente de conhecimento (e significante) para os alunos do segundo ano do curso de Medicina.

Entretanto, o real valor desta ferramenta educacional só poderá ser avaliado após sua ampla utilização por alunos e profissionais das diferentes áreas da saúde nas quais o conhecimento aqui veiculado possa ser útil. Caso seu valor se confirme, vemos com grande interesse a possibilidade de utilizar metodologia semelhante em um leque de outras condições fisiológicas e patológicas, na área tanto da parasitologia, como de outras áreas da saúde.

\section{CONCLUSÃO}

Uma análise dos resultados colhidos nos permite afirmar que o software é de interesse dos alunos, e sua utilização melhora o nível de conhecimento dos usuários, o que pode ser verificado tanto por autoavaliação quanto por questões objetivas. 
Esta nova metodologia ativa de ensino pode ser expandida para novos temas da parasitologia e para outras áreas das ciências médicas e da saúde.

Graças aos resultados observados e às declarações dos alunos que usaram o software, concluímos que ele constitui uma importante ferramenta para auxílio no processo ensino-aprendizado. Espera-se que o material didático criado seja autoaplicável, motivacional e venha a auxiliar professores, alunos de graduação e até mesmo técnicos de laboratório no entendimento, estudo e orientação dessas parasitoses.

Tudo isto se deve ao fato de o software disponibilizar textos atualizados com imagens e vídeos, permitir a interatividade por meio dos quizz, ser de fácil acesso (acessado de qualquer computador ligado à internet e em qualquer horário) e sem custo (o acesso ao software é gratuito).

\section{REFERÊNCIAS}

1. Capra F. O Ponto de Mutação: a ciência, a sociedade e a cultura emergente. São Paulo: Cultrix; 2006.

2. Behrens MA. O paradigma emergente e a prática pedagógica. Petrópolis: Vozes; 2005.

3. Lampert JB. Dois séculos de escolas médicas no Brasil e a avaliação do ensino médico no panorama atual e perspectivas. Gaz Médica da Bahia. 2008;78(supl. 1):31-7.

4. Dunn KE, Rakes GC. Teaching teachers: an investigation of beliefs in teacher education students. Learn Environ Res. 2011;14(1):39-58.

5. Brasil. Ministério da Educação. Conselho Nacional de Educação. Câmara de Educação Superior. Resolução CNE/CES n ${ }^{\circ} 4$, de 7 de novembro de 2001. Diário Of da União. 2001;(9):38.

6. Stenfors-Hayes T, Hult H, Dahlgren LO. What does it mean to be a good teacher and clinical supervisor in medical education? Adv Heal Sci Educ. 2011;16(2):197-210.

7. Mohanna K, Chambers R, Wall D. Developing your teaching style: increasing effectiveness in healthcare teaching. Postgrad Med J. 2007;83(977):145-7.

8. Postareff L, Lindblom-Ylänne S, Nevgi A. The effect of pedagogical training on teaching in higher education. Teach Teach Educ. 2007;23(5):557-71.

9. Pereira AL. As tendências pedagógicas e a prática educativa nas ciências da saúde. Cad Saude Publica. 2003;19(5): $1527-34$

10. Fonseca LM, Góes FS, Ferecini GM, Leite AM, Mello DF, Scochi CG. Inovação tecnológica no ensino da semiotécnica e semiologia em Enfermagem Neonatal: do desenvolvimento à utilização de um software educacional. Texto Context em Enferm. 2009;18(3):549-58.
11. Ramos E. O fundamental na avaliação da qualidade do software educacional. II Simpósio Bras Informática Educ. Porto Alegre; 1991.

12. Brunner M, Moeslinger T, Spieckermann PG. Echocardiography for teaching cardiac physiology in practical student courses. Adv Physiol Educ. 1995;13(1):S2-9.

13. Song S, Burleson PD, Passo S, Messina EJ, Levine N, Thompson CI, et al. Cardiac structure and function in humans : a new cardiovascular physiology laboratory. Adv Heal Sci Educ. 2009;33:221-9.

14. Feijo A. A utilização de métodos alternativos na pesquisa e educação em substituição aos animais não humanos. Rev Med da PUCRS. 2001;11(2):149-56.

15. Jucá SC. A relevância dos softwares educativos na educação profissional. Ciências \& Cognição. 2006;08:22-8.

16. Kreutz LS, Angeloni MN, Hahne MN, Barreto JM. O uso de simulação para o ensino da fisiologia cardíaca. Encuentro Int Tecnol Gerenc y Med para el Sect salud. Lima; 1999. p. 105-7.

17. Minayo MC. Interdisciplinaridade: uma questão atravessa o saber, o poder e o mundo vivido. Med (Ribeirão Preto). 1991;24(2):70-7.

18. Gomes R, Deslandes SF. Interdisciplinaridade na saúde pública: um campo em construção. Rev Lat Am Enfermagem. 1994;2(2):103-14.

19. Perrenoud P. Dez novas competências para ensinar: convite à viagem. Porto Alegre: Artmed; 2000.

20. World Health Oganization. United Nations Protein Advisory Group. Anthropometry in nutritional surveillance: an overview. Bull World Health Organ. 1976;6:2-11.

21. Ferreira H da S. Desnutrição: magnitude, significado social e possibilidade de prevenção. Maceió: Edufal; 2000.

22. Harpham T, Stephens C. Urbanization and health in developing countries. World Health Stat Q. jan 1991;44(2):62-9.

23. Machado ER, Santos DS, Costa-Cruz JM. Enteroparasites and commensals among children in four peripheral districts of Uberlândia , State of Minas Gerais. Rev Soc Bras Med Trop. 2008;41(6):581-5.

24. Santos MG. Conhecimentos sobre helmintoses intestinais de crianças de uma escola de Minas Gerais. Rev Bras Programa Ciências. 1990;42(2):188-94.

25. Pinheiro RO, Breguêz JM, Baptista SC, Teixeira JL, Silva GM. Ocorrência de parasitas entre crianças do pré-escolar de duas escolas em Vassouras, RJ. Rev Bras Farmácia. 2007;88(2):98-9.

26. Macedo HS. Prevalência de parasitos e comensais intestinais em crianças de escolas da rede pública municipal de Paracatu (MG). Rev Bras Análises Clínicas. 2005;37(4):209-13. 
27. Holveck J, Ehrenberg J, Ault S, Rojas R, Vasquez J, Cerqueira $\mathrm{M}$, et al. Prevention, control, and elimination of neglected diseases in the Americas: pathways to integrated, inter-programmatic, inter-sectoral action for health and development. BMC Public Health. 2007;7(6):1-21.

28. Fonseca EOL, Teixeira MG, Barreto ML, Carmo EH, Costa $\mathrm{M}$ da $\mathrm{CN}$. Prevalence and factors associated with geohelminth infections in children living in municipalities with low HDI in North and Northeast Brazil. Cad Saude Publica. 2010;26(1):143-52.

29. Zar JH. Biostatistical Analysis. 5 th. New Jersey: Pearson Prentice Hall; 2010.

30. Dowbor L. Tecnologias do conhecimento: os desafios da educação. Rio de Janeiro: Vozes; 2001. p. 88.

\section{CONTRIBUIÇÃO DOS AUTORES}

Tatiana Damasceno Grincevicius, aluna do Mestrado Profissional Educação nas Profissões da Saúde da Pontíficia Universidade Católica de São Paulo, foi responsável pela execução de todas as etapas do projeto, incluindo aquisição de imagens macroscópicas e microscópicas dos parasitas, elaboração do storyboard, esquemas, textos e software livre, assim como a montagem e aplicação dos questionários e instrumentos de percepção, inclundo a análise estatística dos mesmos.

Suzana Guimarães Moraes, Professora Doutora do Departamento de Morfologia e Patologia da Faculdade de Ciências Médicas da Pontíficia Universidade Católica de São Paulo, orientadora e responsável pela elaboração do projeto assim como a transferência do know how, para a orientanda, das etapas de elaboração dos questionários, instrumentos de percepção e elaboração do software.

\section{CONFLITO DE INTERESSES}

Os autores declaram que não há conflitos de interesse.

\section{ENDEREÇO PARA CORRESPONDÊNCIA}

Tatiana Damasceno Grincevicius

Rua José Marques de Oliveira, 97, Casa B9

Chacaras Reunidas São Jorge - Condomínio Villa do Bosque

Sorocaba - São Paulo

CEP: 18052-490 SP

E-mail: tatigrince@uol.com.br 